\title{
Determination of a critical stress and distance criterion for crack propagation in cutting models of cheese
}

Vandenberghe, Els ${ }^{1,3}$, Charalambides, M.N. ${ }^{2}$, Mohammed, I.K. ${ }^{2}$, De Ketelaere, Bart ${ }^{3}$, De

Baerdemaeker, Josse $^{3}$, Claes, Johan ${ }^{1}$

${ }^{1}$ Lab4Food, Cluster for Bio-engineering Technology, Department of Microbial and Molecular Systems, Leuven Food Science and Nutrition Research Centre (LFoRCe), KU Leuven

Kleinhoefstraat 4, BE-2440 Geel (Belgium)

${ }^{2}$ Department of Mechanical Engineering, Imperial College London

South Kensington Campus, London SW7 2AZ, UK

${ }^{3}$ Division of Mechatronics, Biostatistics and Sensors, University of Leuven

Kasteelpark Arenberg 30, BE-3001 Heverlee (Belgium)

m.charalambides@imperial.ac.uk, bart.deketelaere@biw.kuleuven.be, josse.debaerdemaeker@biw.kuleuven.be,johan.claes@kuleuven.be

corresponding author: johan.claes@kuleuven.be

Paper accepted for publication in Journal of Food Engineering http://dx.doi.org/10.1016/j.jfoodeng.2017.04.005

\begin{abstract}
A critical stress at a critical distance crack propagation criterion is a good way to model the fracture in cheese. This physical criterion states that the crack-tip node debonds when the stress at a specified distance ahead of the crack tip on the assumed crack path reaches a critical value. Although this criterion is already used in other research domains, no consistent information exists on how the critical stress and distance should be determined.

A repeatable method for the determination of this criterion which combines experimental and numerical single edge notched bending tests was acquired. This criterion was validated with wire cutting experiments of cheese. The experimental and numerical results showed the same trend with a clear wire indentation and steady state cutting phase. The determination of a critical stress and distance criterion as proposed in this research is a good approach to model fracture and cutting of cheese.
\end{abstract}

\section{Keywords}

Finite element modeling, fracture, cheese, single edge notched bending, wire cutting 


\section{Introduction}

In recent years the replacement of physical experiments with numerical simulations is becoming increasingly popular in the food industry. A powerful framework to model the mechanical behaviour of food and other biomaterials is finite element modelling (FEM). In the domain of cheese research, finite elements have already been used to model the temperature evolution during cooling (CaroCorrales et al., 2010; Cregan et al., 2013; Lezzi et al., 2011) and to model the salt diffusion during the brining process (Bona et al., 2007). Mechanical processing of cheese has been modelled by Goh et al. (2005) and by McCulloch (2008), who modelled wire cutting and ultrasonic cutting respectively. Research into the field of mechanical cheese processing is important, since sliced and shredded cheese represents a huge share of the cheese market (Gunasekaran \& Ak, 2003).

The amount of literature available that uses finite elements to model the cutting process of cheese is limited. The usefulness of FEM to model mechanical processes that include fracture has been demonstrated in many other research fields which include the microcutting and milling of metals, cutting of wood, planar cutting of bone and many others (Alam et al., 2009; Chen et al., 2013; LeNgoc \& McCallion, 2000; Salahshoor \& Guo, 2014). Depending on the mechanical process and the material that is modelled, different techniques to model fracture and different fracture criteria were used.

It is a challenge to develop reliable FE models capable of accurate prediction of failure with a minimum number of easily determined material parameters. Gamonpilas et al. (2009) performed finite element simulations of wire cutting of starch gels. A failure criterion based on a critical fracture strain was used with a node-release technique. The crack was allowed to propagate in the gel when a maximum principal strain at a distance ahead of the wire attained a critical value. Specifically for cheese, Goh et al. (2005) simulated fracture in wire cutting using a cohesive zone model with a traction-separation law. In the FEM of McCulloch (2008) a critical stress at a critical distance crack propagation criterion was used to model fracture in cheese. This physical criterion states that the crack-tip node debonds when the stress at a specified distance ahead of the crack tip on the assumed crack path, represented by $f$, reaches a critical value, as shown in equation 1 (Li et al., 2002).

$$
f=\sqrt{\left(\frac{\sigma_{x x}}{\sigma_{f}}\right)^{2}+\left(\frac{\tau_{x y}}{\tau_{f}}\right)^{2}}
$$

In this equation $\sigma_{\mathrm{xx}}$ is the stress component in the perpendicular direction to the crack path, $\tau_{\mathrm{xy}}$ is the shear stress in the direction along the crack path and $\sigma_{\mathrm{f}}$ and $\tau_{\mathrm{f}}$ are the failure normal and shear stresses of the material. The initially bonded nodes separate when $\mathrm{f}=1 \pm \Delta \mathrm{f}$, where $\Delta \mathrm{f}$ is the given tolerance (Li et al., 2002).

Several researchers have used such a critical stress criterion when modelling the cutting process of other materials, such as metal, polyurethane foam and epoxy resin (Shet et al., 2003; Shet \& Deng, 2003; Lucas et al., 2006). Although this criterion is regularly used, no consistent information exists on how the critical stress and distance should be determined. Martiny et al. (2013) studied mode I failure 
of metal-to-metal adhesive joints and identified the failure criteria by an inverse analysis, i.e. by choosing the critical stresses and distances in order to get the best possible agreement between the numerical predictions and the experimental data. Li et al. (2002), who studied the orthogonal metal cutting process, also stated that trial-and-error simulations were generally needed to determine this criterion. McCulloch (2008) proposed the use of single edge notched bending tests (SENB) to determine the critical stress and distance. In these SENB tests beam shaped samples with a notch cut in the lower edge are placed on two supporting pins. A probe is lowered on the middle of the sample until the inflicted bending causes material failure.

The method described by McCulloch (2008) was a good starting point, but had also some shortcomings. Firstly, the forces from the SENB models did not correspond with the experimental tests. The experimental forces produced in the SENB tests were considerably lower than the finite element predictions for the material models. After $1 \%$ strain the difference between the experimental and numerical forces already exceeded one order of magnitude. Secondly, the point of cheese fracture that was used as a boundary condition in the SENB models of McCulloch (2008) was arbitrarily set at $1 \mathrm{~mm}$ deformation for each cheese sample. However, research has shown that the deflection of the cheese samples needed to initiate fracture varies between different cheese samples. An individual determination of the fracture point allows a more accurate determination of the critical stress criterion. Thirdly, when using hyperelastic cheese models McCulloch took the stress at the initial crack tip as the critical stress. However, at this point the results are dependent on the mesh density and the radius of the keyhole used in the models. Mesh refinement or changes in the keyhole dimensions influence the stress results at the crack tip without leading to a convergence. It is necessary to use the critical stress at a distance from the crack tip. Lastly, McCulloch's method was not repeatable and standardized due to the fact that his samples and the initial cut were made manually with a scalpel blade.

In this research the method as first proposed by McCulloch is further developed. Then wire cutting models of cheese are constructed to examine the validity of the fracture propagation criterion.

\section{Material and methods}

The determination of the critical stress and distance criterion as described in this work is based on a combination between physical experiments and finite element models. Figure 1 gives an overview of the general methodology. 


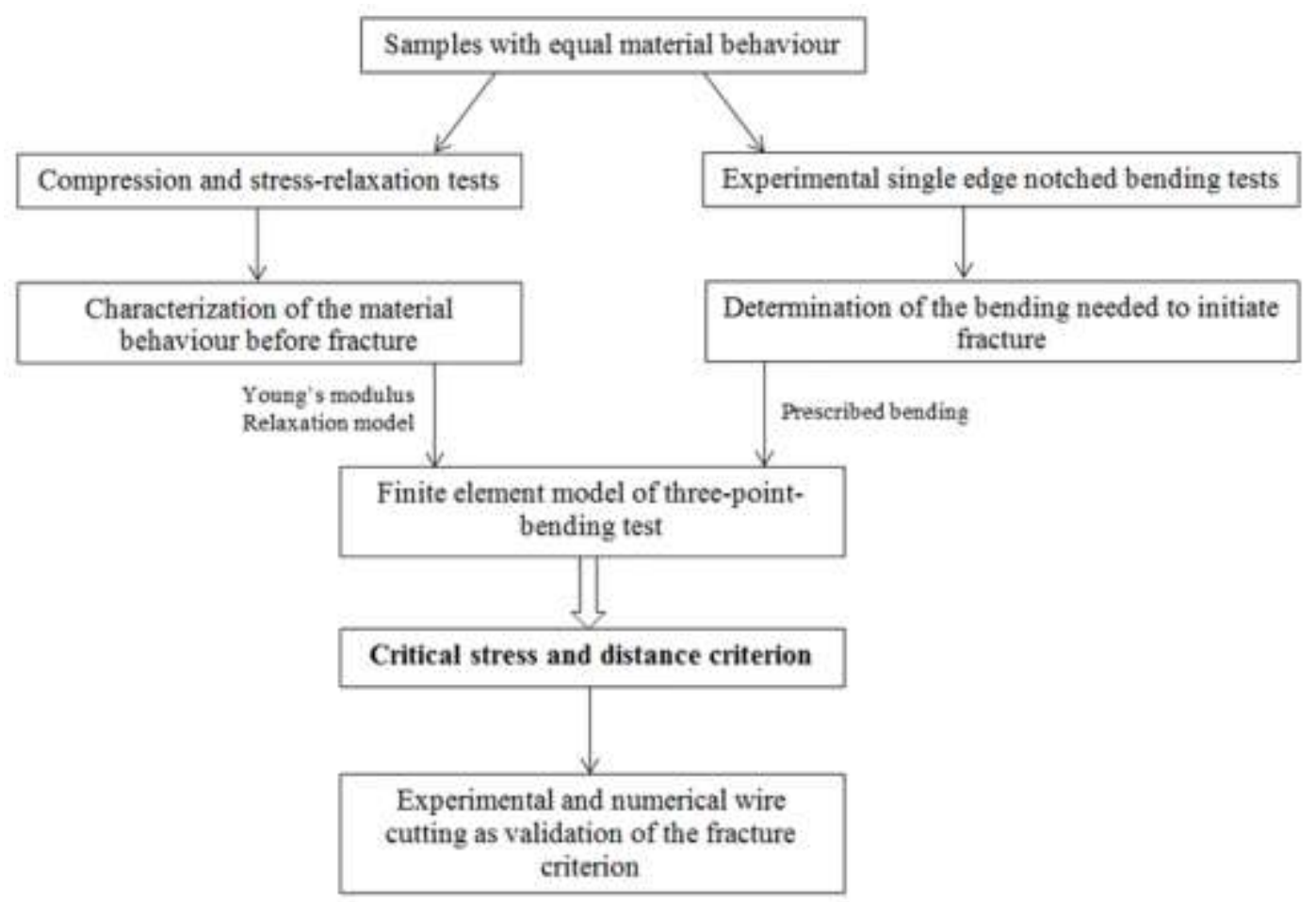

Figure 1: Methodology to determine and validate the critical stress at a critical distance criterion Each of the main steps will be clarified separately in the following paragraphs.

\subsection{Material behaviour}

When only small deformations are applied, cheese behaves as a linear viscoelastic material (Gunasekaran \& Ak, 2003). During processing of cheese, such as cutting, fracture will already occur after small deformations. Therefore the assumption was made that including the non-linear material behaviour of cheese in the models in order to mimick the behavior of cheese during cutting was not necessary.

Linear viscoelastic behaviour is often modeled using the Generalized Maxwell model as described in Vandenberghe et al. (2014). This model consists of a Hookean spring defined by Young's modulus which is connected in parallel with a series of viscous Maxwell elements. The relaxation behaviour of these elements is then represented by a Prony series expansion (eq.2), where $\tau_{\mathrm{i}}$ are time constants for $\mathrm{i}$ $=1 \ldots \mathrm{n}_{\mathrm{G}}$, respectively. $\mathrm{G}_{\infty}$ is the residual Prony coefficient, representing the material behaviour at an infinite relaxation time. The dimensionless constants $\mathrm{G}_{\mathrm{i}}$ and $\mathrm{G}_{\infty}$ are normalized so that they add up to 1 (eq.3).

$$
\begin{aligned}
& G(t)=G_{\infty}+\sum_{i=1}^{n_{G}} G_{i} e^{\left(-t / \tau_{i}\right)} \\
& G_{\infty}+\sum_{i=1}^{n_{G}} G_{i}=1
\end{aligned}
$$




\subsection{Selection of samples with equal material behaviour}

This research was performed on 4 weeks old Gouda cheese. The cheese block had standard dimensions of $47 \times 30 \times 10 \mathrm{~cm}^{3}$. Previous research showed the presence of spatial gradients of the fundamental material parameters in Gouda cheese (Vandenberghe et al., 2014). The design of the experiments takes this heterogeneity into account, as well as the previously detected symmetry in the length and width of a cheese block (Vandenberghe et al., 2014). .

The block of Gouda cheese was divided in a middle (M) and two side (S) sections. Both the middle as well as the side sections contain 4 slices in total and those slices were considered to be equal (M1 to M4 and S1 to S4) as shown in figure 2.

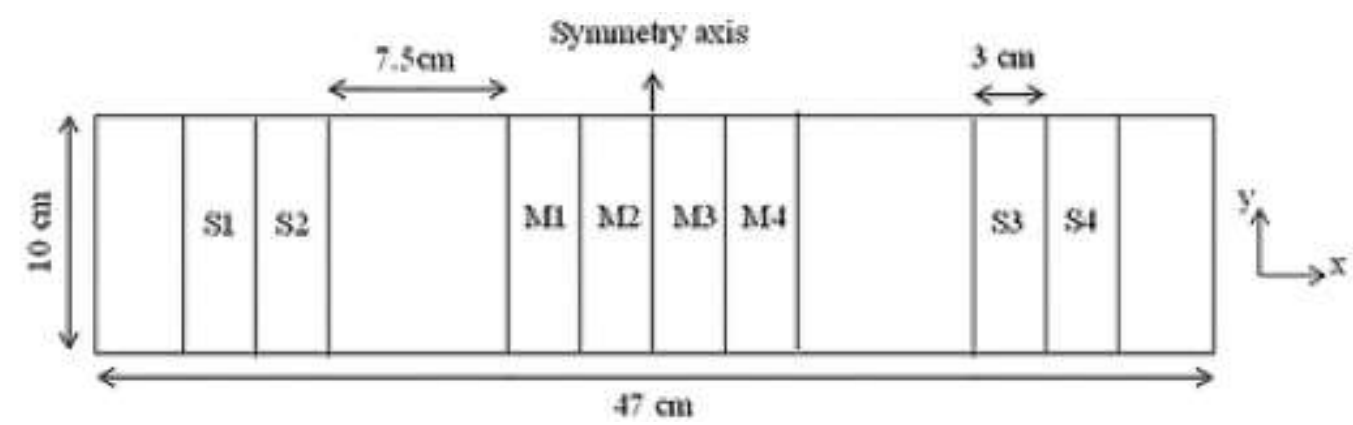

Figure 2: Division of a cheese block in slices

Each slice was divided into two halves that were considered to have the same mechanical properties due to symmetry. In each half of a slice, three locations with differing material properties were measured, i.e. the upper corner, the lower corner and the middle point (fig. 3). Due to the similarity of the slices per section and the similarity of the slice halves (symmetry) 8 samples with similar properties could be taken for each location. Two samples were used for compression tests (§2.3), two for stress-relaxation tests (\$2.3), two for single edge notched bending tests (§2.4) and two for wire cutting tests $(\$ 2.5)$. The samples were assigned randomly to the different measurements.

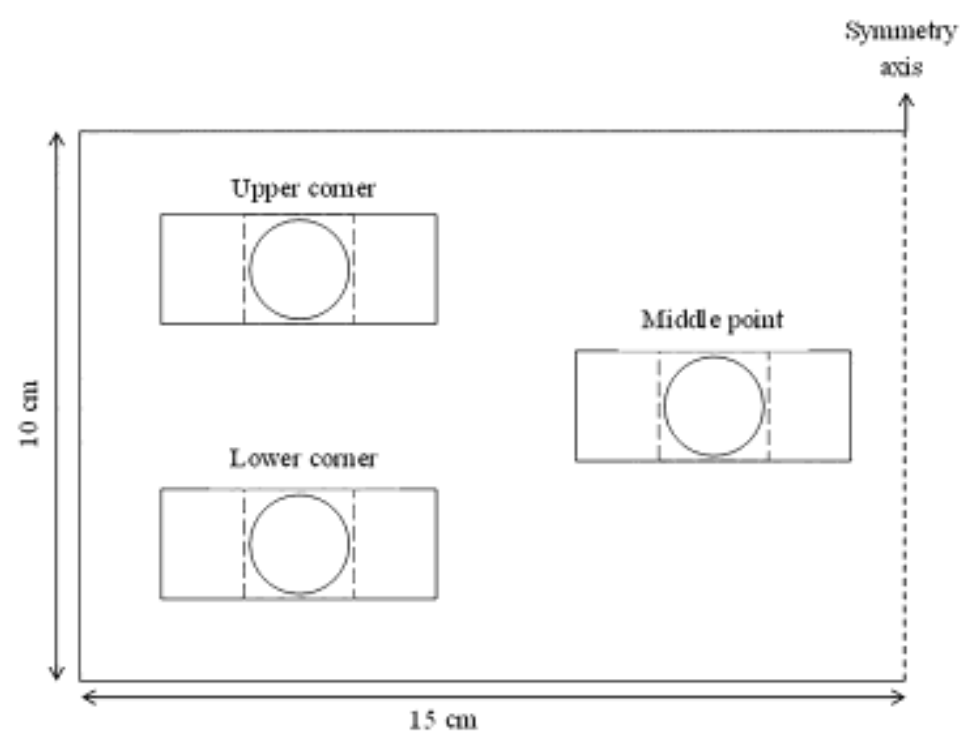

Figure 3: Sample locations in a slice half: circles represent stress relaxation and compression samples, full line rectangles represent the SENB samples, dotted line rectangles represent the wire cutting samples 


\subsection{Compression and stress relaxation tests}

Young's modulus was determined on cylindrical samples with a diameter of $18 \mathrm{~mm}$ and a height of 27 $\mathrm{mm}(+/-0.5 \mathrm{~mm})$ during compression tests performed using a Texture Analyser TA.XT2i (Stable Microsystems, UK) with a flat compression plate (diameter $7.5 \mathrm{~cm}$ ). The unlubricated samples were compressed at $0.83 \mathrm{~mm} / \mathrm{s}$ untill a true strain of $80 \%$ was reached to determine Young's modulus as well as the fracture stress and strain, as described in Vandenberghe et al. (2014).

Stress relaxation tests were performed to determine the time-dependent behavior of the visco-elastic material. The samples were compressed by $5 \mathrm{~mm}$, i.e. a true strain of $17 \%$, at a speed of $6 \mathrm{~mm} / \mathrm{s}$. This strain was maintained for 180s. The corresponding stress was registered as function of time. The normalized relaxation stresses were calculated by normalization with the peak compression stresses (at the maximum true strain) and Prony series were fitted to the obtained curves.

The fitting of the Prony series was performed using a Solver tool of Excel (Microsoft, U.S.). A best fit was searched based on the least squares method. A model with 4 exponential terms $\left(G_{1}, G_{2}, G_{3}\right.$ and $\mathrm{G}_{4}$ ) with relaxation times $0.1,1,10$ and 100 s and a residual term $\mathrm{G}_{\infty}$ at an infinite relaxation time was selected, following equations 2 and 3 .

\subsection{Experimental single edge notched bending (SENB) tests}

Experimental SENB-tests were performed to determine the deflection at which the cheese starts to fracture. The tests were performed on beam-shaped cheese samples $\left(2 \times 2 \times 5 \mathrm{~cm}^{3}\right)$. These samples were cut with a specially designed rectangular cutter. At the middle of the samples an initial notch of $4 \mathrm{~mm}$ depth was made with a knife blade attached to a TA.XT2i texturometer (Stable Microsystems, UK). This notch was necessary to obtain the fracture initiation. Figure 4 shows the experimental test set-up of the SENB-tests.

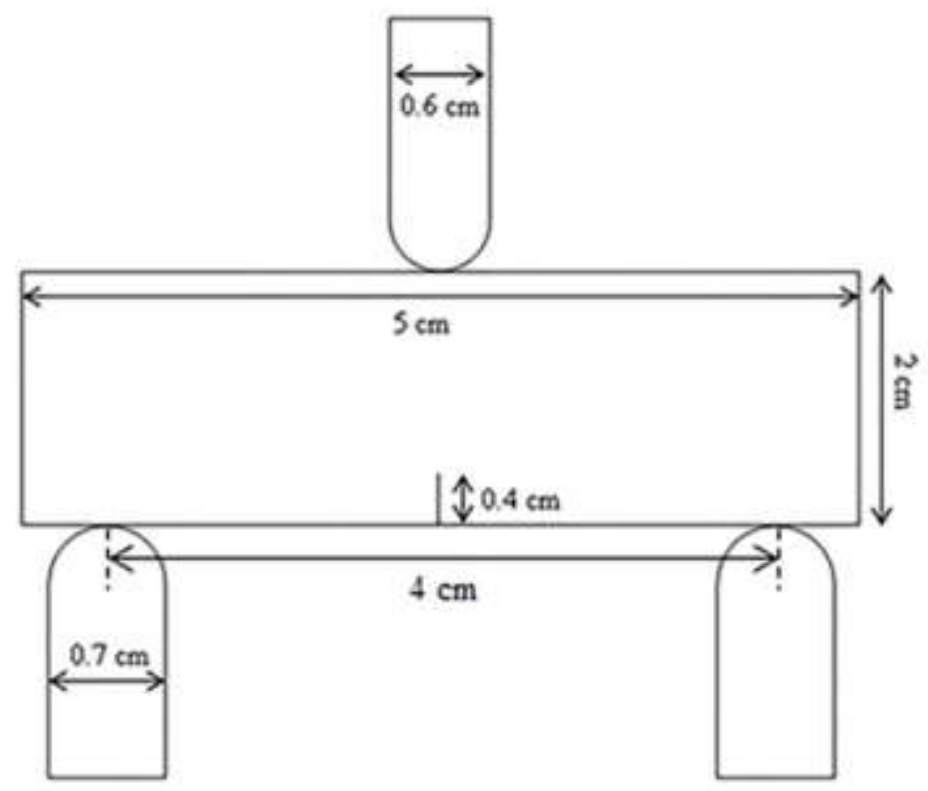

Figure 4: Set-up of the experimental single edge notched bending tests on $2 \times 2 \times 5 \mathrm{~cm}^{3}$ cheese samples 
The SENB-tests were performed with the TA.XT2i texturometer equipped with a $5 \mathrm{~kg}$ load cell. Each sample was subjected to a deflection of $10 \mathrm{~mm}$ at the midpoint. Three testing speeds, i.e. $0.1 \mathrm{~mm} / \mathrm{s}$, $0.5 \mathrm{~mm} / \mathrm{s}$ and $1 \mathrm{~mm} / \mathrm{s}$, were used. The speeds assigned to the different samples differed between the various sample locations. The different speeds were assigned randomly to the different sample locations. Table 1 gives an overview of the different testing speeds in each section and location.

Table 1: SENB speed, cutting speed and wire diameters as used for each cheese section and sample location

\begin{tabular}{cccccccc} 
& \multicolumn{2}{c}{$\begin{array}{c}\text { SENB speed } \\
(\mathrm{mm} / \mathrm{s})\end{array}$} & \multicolumn{2}{c}{$\begin{array}{c}\text { Cutting speed } \\
(\mathrm{mm} / \mathrm{s})\end{array}$} & \multicolumn{2}{c}{ Wire diameter $(\mathrm{mm})$} \\
\cline { 2 - 7 } & middle & side & middle & side & middle & side \\
\hline Upper corner & 0.5 & 0.1 & 0.5 & 0.1 & 1.1 & 0.8 \\
Lower corner & 0.5 & 1 & 0.5 & 1 & 0.8 & 0.8 \\
Middle point & 1 & 0.1 & 1 & 0.1 & 1.1 & 1.1
\end{tabular}

It should be noted that although the same speeds were used during the SENB tests and the wire cutting experiments, this does not automatically mean that the cracks in these samples propagate at the same speed (Gamonpilas et al., 2009). However, this does not affect the results in this study much, since there was a weak dependence of the critical stress and distance on the test speed (table 4).

The reaction force on the upper probe was monitored as a function of the deflection of the samples up till the point of fracture initiation.

This point of fracture initiation was determined by recording the SENB-tests (full HD, 29 frames per second), using a DSLR Nikon 3200 camera (Nikon, Japan) with an AF-S 150mm micro lens. The video images were processed with Vegas Pro 11 (Sony Creative Software, USA) to determine the initial fracture point and the deflection at which this fracture occurred. Figure 5 shows a frame of such video recording. The single edge notched bending speed in this test was $0.1 \mathrm{~mm} / \mathrm{s}$. The images below show the cheese after $0 \mathrm{~mm}, 1 \mathrm{~mm}, 2 \mathrm{~mm}, 3 \mathrm{~mm}, 4 \mathrm{~mm}$ and $5 \mathrm{~mm}$ of bending. 


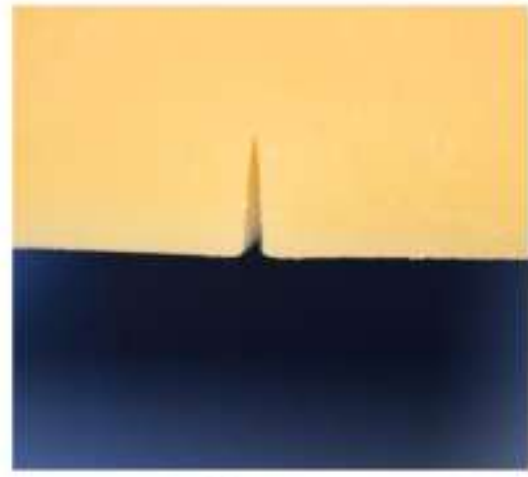

(a)

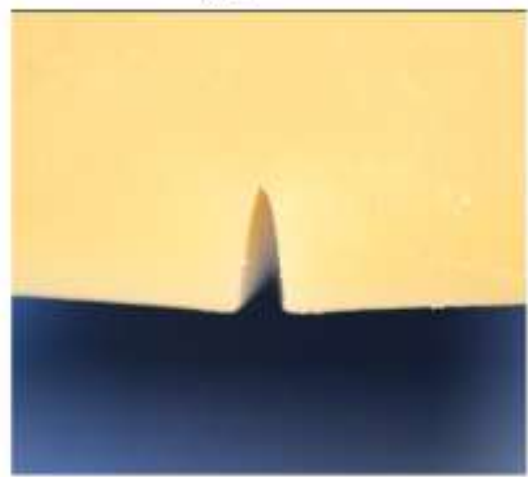

(c)

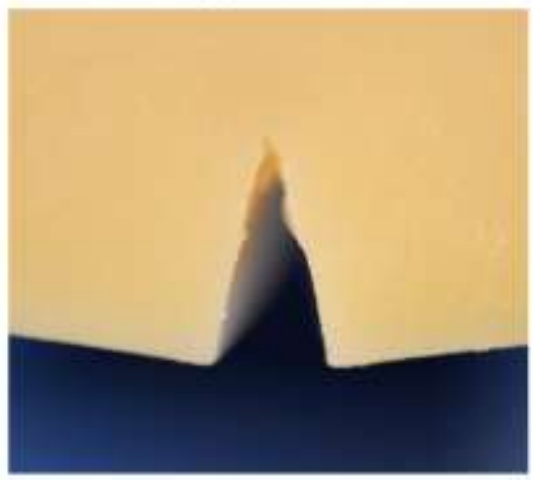

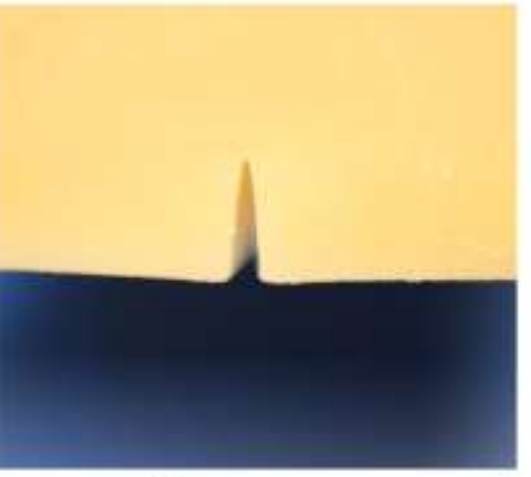

(b)

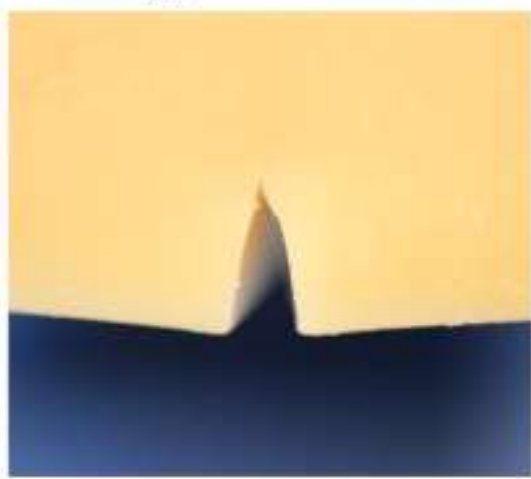

(d)

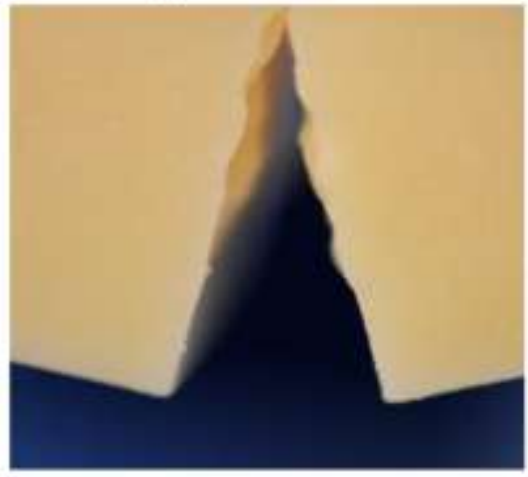

Figure 5: Video frames of fracture initiation in a cheese sample during a single edge notched bending test after (a) $0 \mathrm{~mm}$ (b) $1 \mathrm{~mm}(c) 2 \mathrm{~mm}$ (d) $3 \mathrm{~mm}$ (e)4mm and (f) $5 \mathrm{~mm}$ of bending.

\subsection{Experimental wire cutting tests}

Experimental wire cutting tests were performed with the TAXT2i texturometer on cubic cheese samples $\left(2 \times 2 \times 2 \mathrm{~cm}^{3}\right)$. All cheese samples were cut through the middle with a wire cutting device as shown in figure 6. 


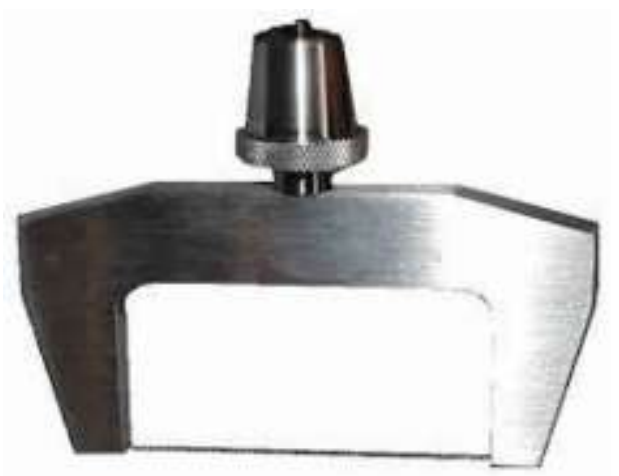

Figure 6: Wire cutting device

Steel wires with a diameter of $0.8 \mathrm{~mm}$ or $1.1 \mathrm{~mm}$ were clamped tight in the wire cutting device (table 1). Wires with a smaller diameter could not be used due to practical limitations. The measurements were performed at $0.1 \mathrm{~mm} / \mathrm{s}, 0.5 \mathrm{~mm} / \mathrm{s}$ or $1 \mathrm{~mm} / \mathrm{s}$ for samples of the middle or side section respectively (see Table 1).

\subsection{Finite element models of single edge notched bending tests}

All the finite element analyses were carried out using the software Abaqus 6.12 (Simulia, France).

For each section and each sample location a SENB-test model was constructed, resulting in 6 different material parameter sets (see results section for the specific parameters).

Plane strain 2D models were constructed. Considering the symmetry of the test set-up only one half of the model was analysed as shown in figure 7.

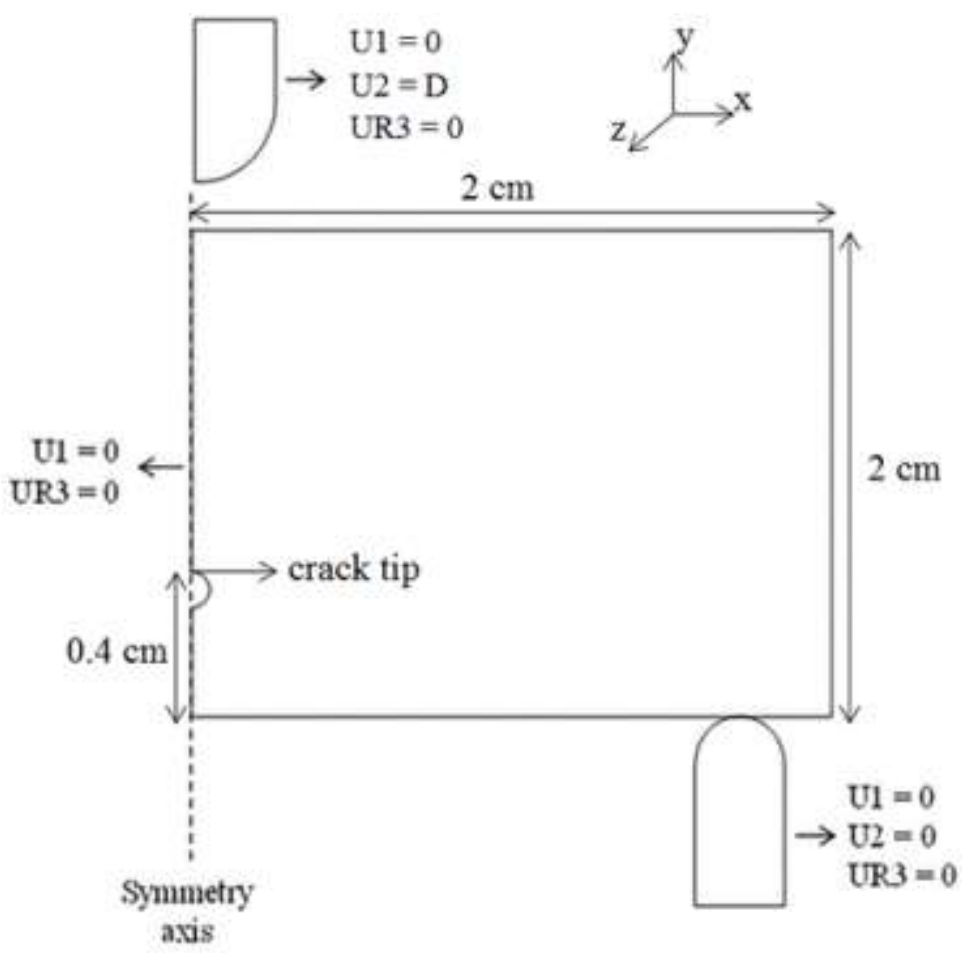

Figure 7: Schematic of the SENB model including the boundary conditions, with D: deflection needed before fracture initiation, U1:translational movement in the x-direction, U2: translational movement in the y-direction, UR3: rotational movement in the z-direction 
Both the upper and the lower probe were modelled as rigid bodies. The bottom probe was fixed (U1 = $\mathrm{U} 2=\mathrm{UR} 3=0)$. The upper probe was constrained in the horizontal direction $(\mathrm{U} 1=0)$ but allowed to move freely in the vertical direction $(\mathrm{U} 2=\mathrm{D})$. The probe was prescribed to move downward at the same speeds as in the experiments (table 1). The downward movement was limited to the deflection distance required to initiate fracture.

The cheese material was modelled using four noded, plane strain, solid elements. The total cheese model consisted of 30930 elements. Figure 8 illustrates the mesh of the entire cheese model. It can be seen that a finer mesh was used in the upper left corner and the lower right corner, where the cheese makes contact with the upper and lower probe. The accuracy and convergence of the results with this mesh density was confirmed by performing mesh sensitivity studies.

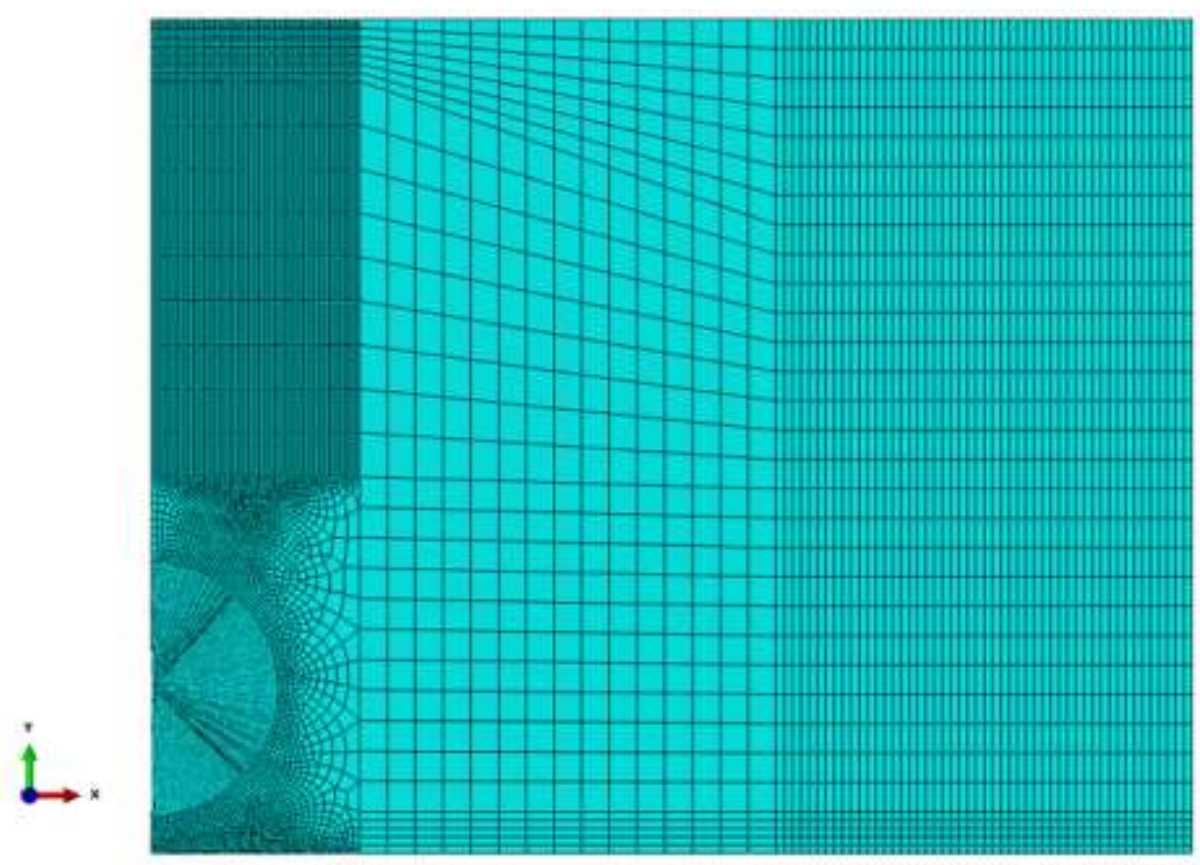

Figure 8: Mesh of the entire cheese model

The circular mesh area at the lower left side of the cheese is the area surrounding the crack tip where fracture will initiate. This crack tip was represented as a key hole to prevent numerical problems, as can be seen in figure 9 . The key hole was circular with a radius of $0.5 \mathrm{~mm}$.
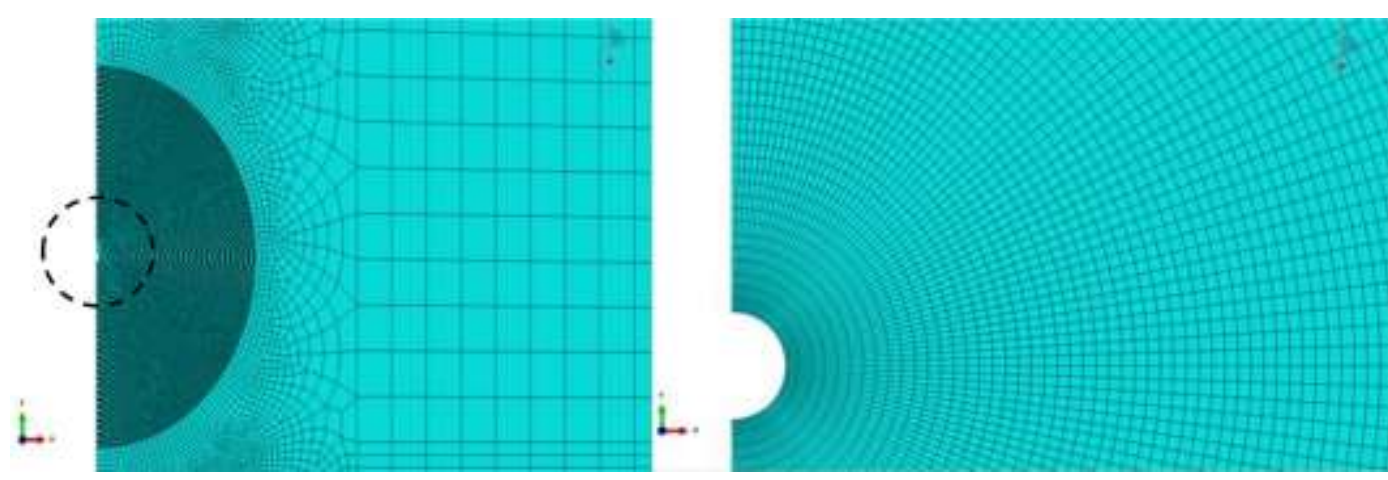

Figure 9: (a) mesh of the crack tip zone, (b) zoomed view of the mesh around the crack tip 
Figure 9 (a) illustrates the mesh zone around the key hole where the fracture will initiate. A zoomed view of (a) is represented in figure 9 (b) to illustrate the partitioning technique used to ensure an organized structured continuum and to highlight the density of the mesh surrounding the crack tip. The total number of linear quadrilateral elements in the circular area around the crack tip was 25000 . This is $81 \%$ of the number of elements in the entire cheese model. Thus it is clear that the mesh in the vicinity of the crack tip was very fine. Along the crack path (i.e. the vertical symmetry line above the key hole), the distance (undeformed) between the nodes was $15 \mu \mathrm{m}$. Mesh sensitivity studies were performed to validate the mesh density.

A direct solver was used with the full Newton's method to iteratively solve the equilibrium equations. Time incrementation happened automatically with a maximum increment size of $1 / 100^{\text {th }}$ of the total time period. The model was run using a VISCO step. Such a step is used for a stress/displacement analysis with a time dependent material response. The VISCO procedure implements time integration of the material behaviour in consecutive temporal increments (Aydiner et al., 2005). To account for geometric non-linearity due to distortion of the mesh the NLGEOM option was used.

For each SENB model, the reaction force on the upper probe as a function of the deflection at the centre of the cheese sample was calculated. This force was then compared with the force on the probe measured in the experimental SENB-tests.

\subsection{Numerical modeling of wire cutting tests}

The measured material parameters and failure criteria were implemented in FEM for wire cutting simulations on cheese samples. Figure 10 shows a schematic of these 2D models. Due to symmetry only half of the geometry was modelled.

The steel wire was modelled as a circular rigid body with a diameter of $0.8 \mathrm{~mm}$ or $1.1 \mathrm{~mm}$ as shown in table 1. It was constrained in the horizontal direction but allowed to move in the vertical direction for $10 \mathrm{~mm}$. The displacement speed of the wire was either $0.1 \mathrm{~mm} / \mathrm{s}, 0.5 \mathrm{~mm} / \mathrm{s}$ or $1 \mathrm{~mm} / \mathrm{s}$, as was used during the experimental SENB tests (table 1).

The cheese was modelled as a linear visco-elastic material using 2D linear, plane strain elements. Figure 11 (a) shows the mesh of the entire cheese model. An expanded view of this mesh in the vicinity of the crack path is shown in figure 11 (b). 

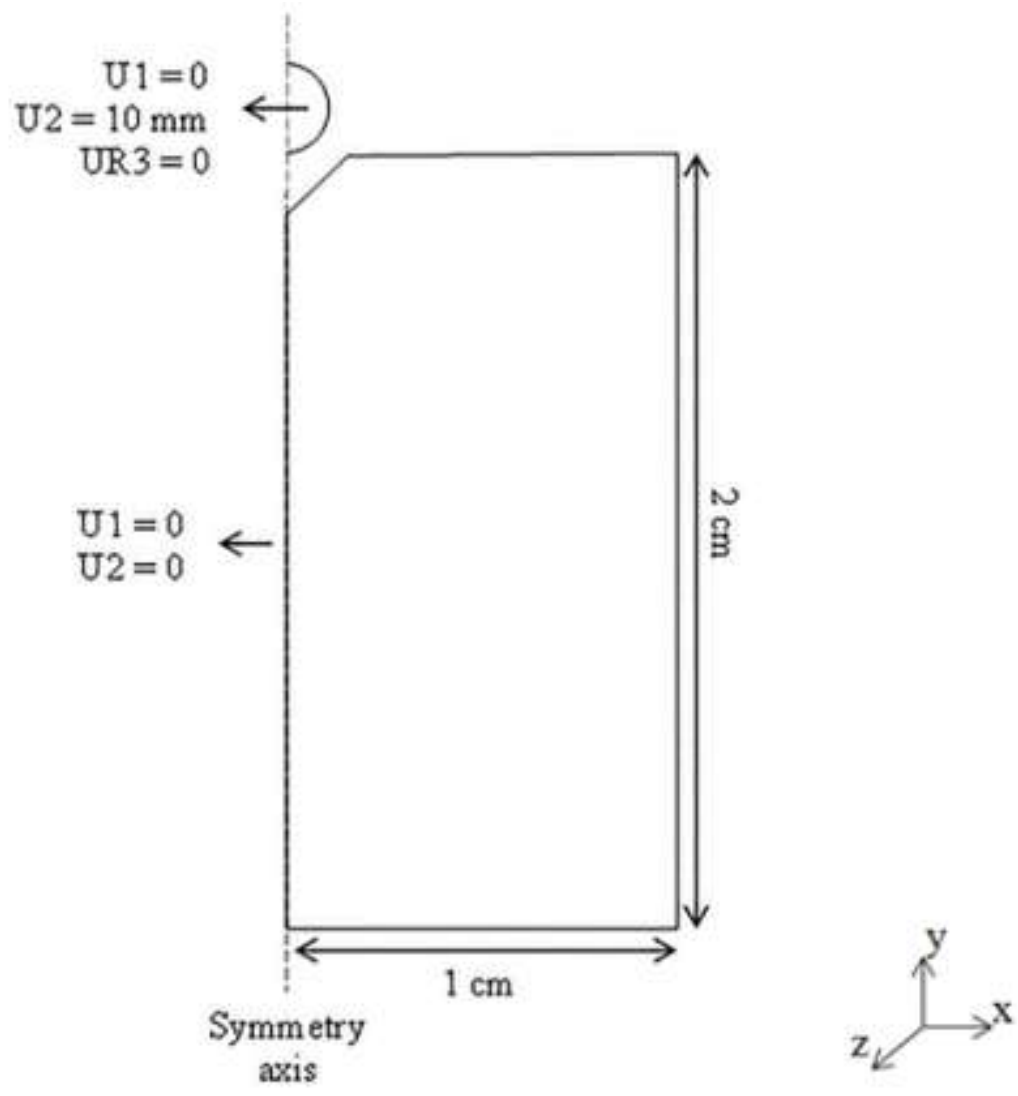

Figure 10: Schematic of the wire cutting model including the boundary conditions; U1: translational movement in the x-direction, U2: translational movement in de y-direction, UR3: rotational movement in the $z$-direction

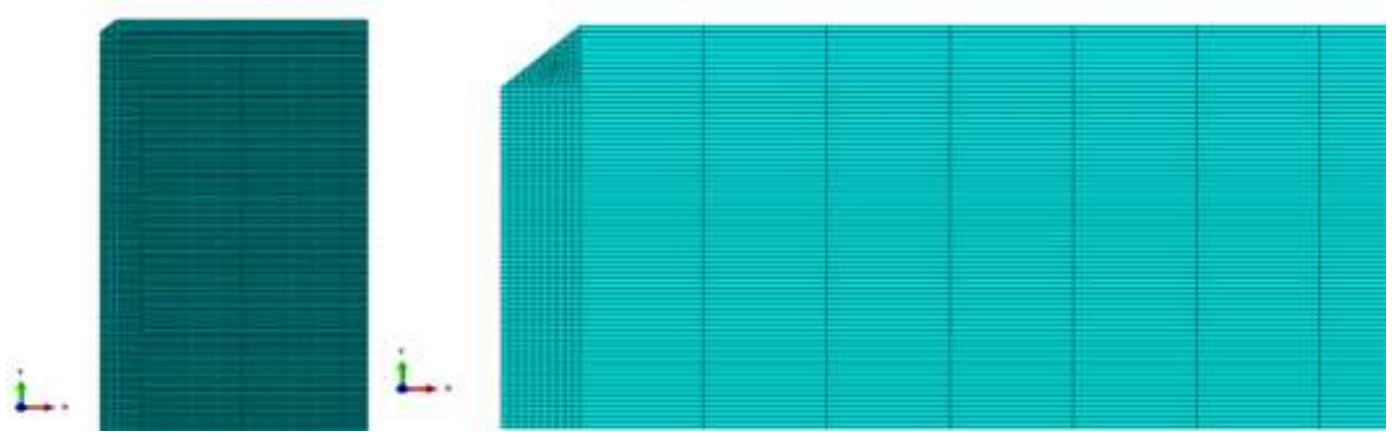

Figure 11: (a) Mesh of the entire cheese model, (b) details of the mesh in the vicinity of the initial cutting area

It is clear from figure 11 that a finer mesh was used in the vicinity of the crack line. The entire cheese model consisted of 8010 linear elements, of which 7860 elements were quadrilateral and 150 elements were triangular. The triangular elements were assigned to the area around the initial opening in the cheese block as shown in figure 11. This initial opening was necessary to obtain numerical stability and to enable crack initiation. The fracture initiation criterion examined in this research requires that the wire initially resides within the tip of the theoretical crack to allow the edges of the wire to push against the walls of the crack. This way stresses normal to the crack flanks can be generated (McCulloch, 2008). 
To obtain fracture in the model, the *DEBOND option available in Abaqus was used together with the critical stress criterion.

The principle of this option is that the nodes on the symmetry line are tied to an analytical rigid line. The translational movement of the wire into the material causes the critical stress condition at a prespecified distance ahead of the crack tip to be reached. This leads to a debonding of the tied nodes from the rigid line, releasing the constraints on the first node and allowing it to move in any degree of freedom. This way a crack propagates along the symmetry line. The analytical rigid line used to tie these nodes was placed on the symmetry line.

For this model, a direct solver with Newton's method was used similarly to the SENB-models. Timedependent analysis was used with a VISCO step. Geometric non-linearity was also accounted for with the NLGEOM option.

For each model, the reaction force on the wire as a function of the cutting depth was derived.

\section{Results and discussion}

\subsection{Material parameters}

The Young's moduli and the Prony coefficients were determined with compression and stress relaxation tests for each section and location in the cheese block.

Table 2 shows the Young's moduli for each section and location. Table 3 shows the Prony coefficients.

Table 2: Young's moduli ( $\mathrm{kPa}$ ) at each section and location

\begin{tabular}{ccc} 
& \multicolumn{2}{c}{ Young's moduli } \\
\cline { 2 - 3 } & Middle & Side \\
\hline Upper corner & 1039 & 1171 \\
Lower corner & 987 & 1023 \\
Middle point & 588 & 664
\end{tabular}

Table 3: Prony coefficients at each section and location, UC: upper corner, LC: lower corner, MP: Middle point

\begin{tabular}{cccccc|ccccc}
\multicolumn{7}{c|}{ Middle } & \multicolumn{5}{c}{ Side } \\
\cline { 2 - 11 } & $\mathrm{g}_{1}$ & $\mathrm{~g}_{2}$ & $\mathrm{~g}_{3}$ & $\mathrm{~g}_{4}$ & $\mathrm{~g}_{\infty}$ & $\mathrm{g}_{1}$ & $\mathrm{~g}_{2}$ & $\mathrm{~g}_{3}$ & $\mathrm{~g}_{4}$ & $\mathrm{~g}_{\infty}$ \\
UC & 0.130 & 0.234 & 0.181 & 0.255 & 0.199 & 0.133 & 0.232 & 0.183 & 0.258 & 0.194 \\
LC & 0.141 & 0.238 & 0.179 & 0.256 & 0.185 & 0.134 & 0.239 & 0.185 & 0.244 & 0.199 \\
$M P$ & 0.139 & 0.242 & 0.187 & 0.254 & 0.178 & 0.134 & 0.236 & 0.190 & 0.260 & 0.180
\end{tabular}


These results confirmed the findings in Vandenberghe et al. (2014) that Young's modulus is the highest in the upper corner and the lowest in the middle point. The residual Prony coefficient $\mathrm{G}_{\infty}$ was generally lower in the middle point than in the corner locations. This is also in accordance with the findings of Vandenberghe et al. (2014).

Based on Gunasekaran \& Ak (2003) a Poisson's ratio of 0.45 was used in the cheese models for each section and location.

\subsection{Determination of the critical stress and distance}

From each SENB model the $\sigma_{\mathrm{xx}}$ stress components in the nodes on the crack line were derived when the upper probe caused the same sample deflection as the experimentally determined deflection needed for fracture. The $\sigma_{\mathrm{xx}}$ stress components were derived as a function of the distance of the nodes from the crack tip.

Figure 12 depicts a close-up of the deformed model near the crack tip at the point of fracture and shows the $\sigma_{\mathrm{xx}}$ stress distribution (eq. 1). This model represents the upper corner sample of the middle cheese section.

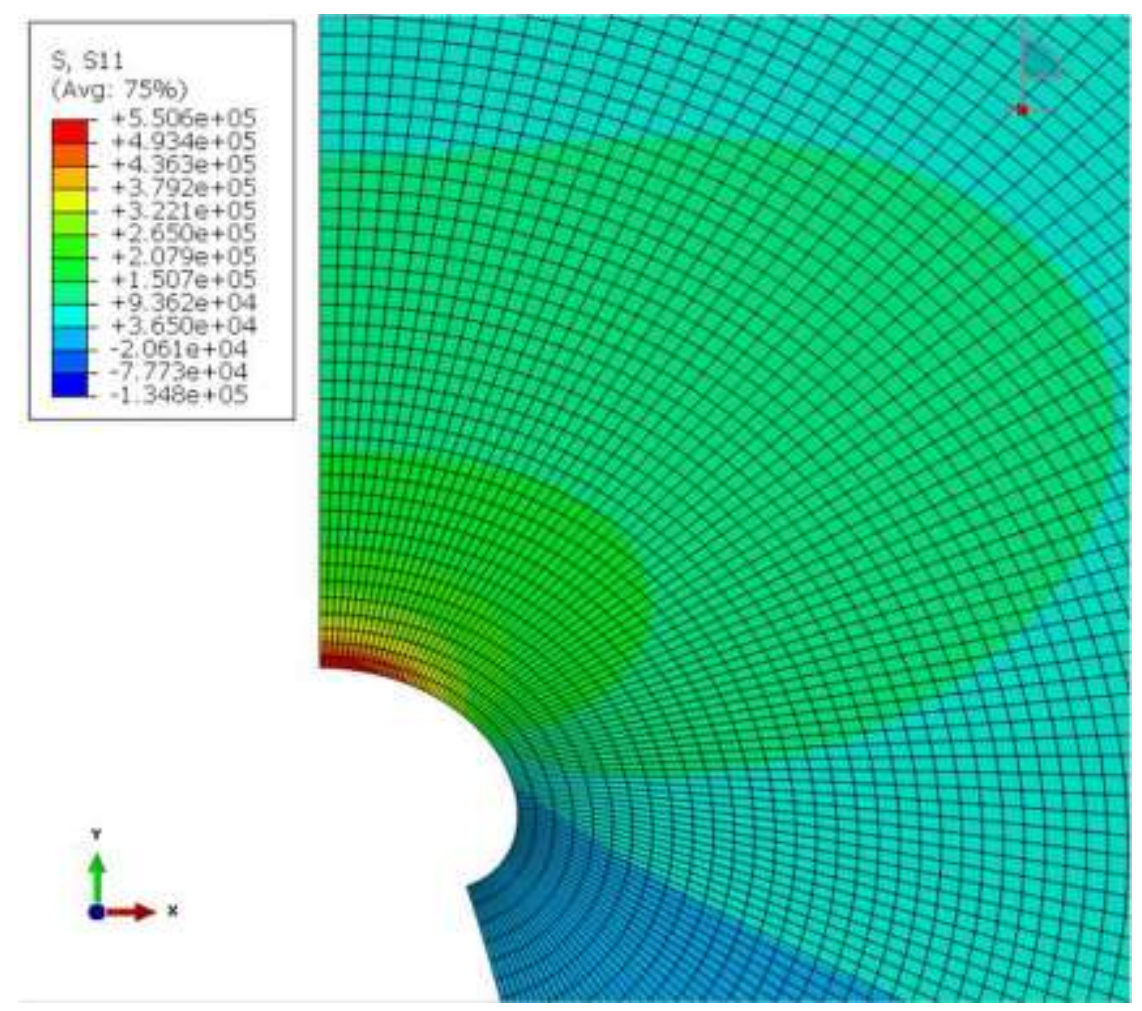

Figure 12: $\sigma_{\mathrm{xx}}$ output of the SENB model near the crack tip

The vertical line in figure 12 that represents the symmetry line is equal to the assumed fracture line. The $\sigma_{\mathrm{xx}}$ values of each node on this line are extracted as a function of the distance of these nodes from the crack tip. 
Figure 13 shows typical $\sigma_{\mathrm{xx}}$ values as a function of the distance of the nodes from the crack tip at the point of assumed fracture. The results shown in this figure are related to the output of the model shown in figure 12.

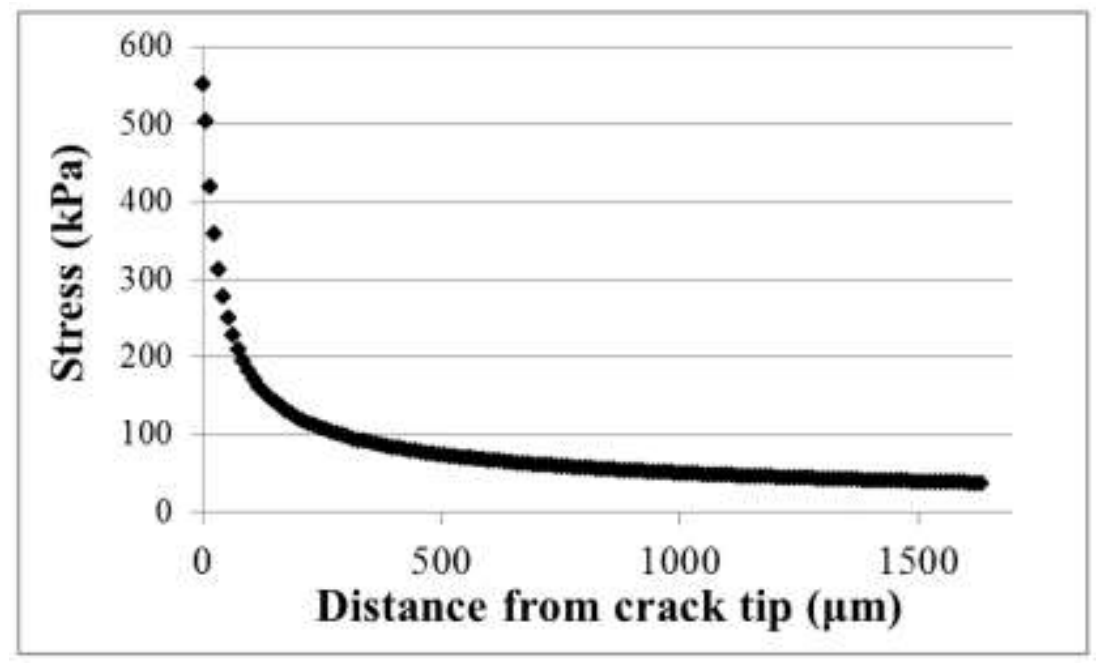

Figure 13: $\sigma_{x x}$ stress at the nodes in front of the crack in function of the distance from the crack tip (upper corner location in middle cheese section)

The maximum stress occurred directly at the crack tip (i.e. at a distance of $0 \mu \mathrm{m}$ ). A preliminary sensitivity analysis showed that the stresses in close proximity to the crack tip were strongly influenced by model choices such as the mesh density and the radius of the keyhole introduced at the crack tip. Figure 14 shows the results of $\sigma_{\mathrm{xx}}$ as a function of the distance of the nodes from the crack tip for different radii of the keyhole. The legend shows the different radii of the keyholes.

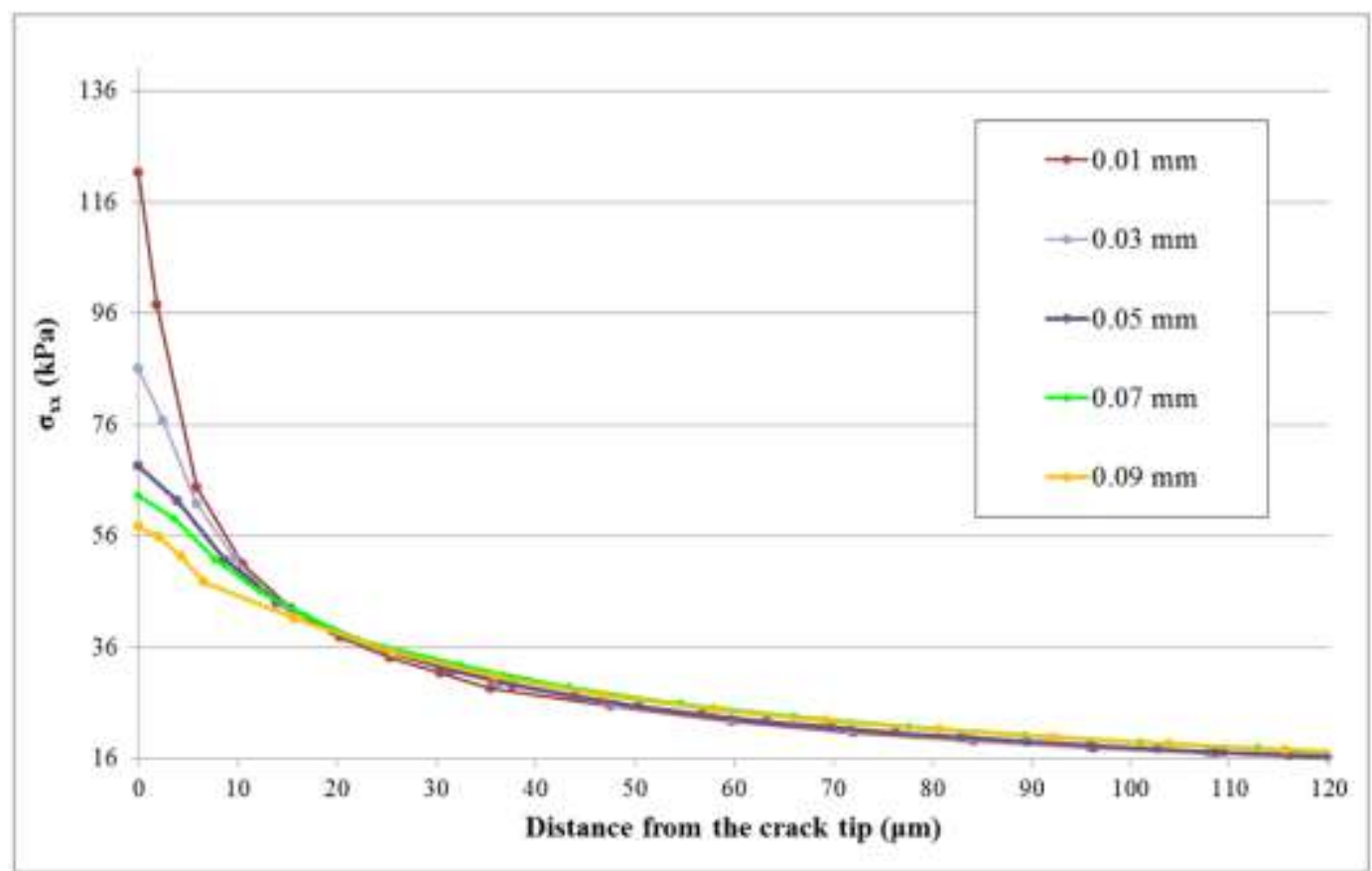

Figure 14: $\sigma_{x x}$ in function of distance of the nodes from the crack tip for different radii of the keyhole 
Mesh refinement or adaptations in the radius did not lead to convergence of the results. Further from the crack tip, however, all $\sigma_{\mathrm{xx}}$ values did converge to one solution irrespective of the radius of the keyhole. This can also be seen on figure 14 . At a distance of $100 \mu \mathrm{m}$ convergence was reached for each data set. Therefore the node in closest proximity of the $100 \mu \mathrm{m}$ distance from the crack tip was determined for each SENB model. The fracture criterion was then determined as the $\sigma_{\mathrm{xx}}$ values in that node and the exact distance of the node from the crack tip.

It was examined whether another distance (further from the crack tip) and its corresponding stress would lead to other fracture behaviour in the SENB-models. For this purpose different fracture distances ranging from $50 \mu \mathrm{m}$ to $400 \mu \mathrm{m}$ were chosen, and their corresponding stresses were derived from the same original SENB model. To check the influence of the chosen distance and stress, the SENB-models as described in $\$ 2.6$ were slightly modified. Firstly, the nodes on the symmetry line were bonded to an introduced middle line. They will debond from this line when the fracture criterion is met. Secondly, the downward movement of the upper probe was set to exceed the depth needed to initiate fracture. The simulations showed that, regardless of the chosen distance, the fracture in each SENB-model occurred at exactly the same compression depth. This showed that the critical distance and the critical stress related to this distance can be chosen arbitrarily when respecting a minimal distance from the crack tip. Table 4 gives the critical stresses and their distances for each cheese section and each sample location.

Table 4: Critical stresses and their corresponding distances for each cheese section and sample location

\begin{tabular}{ccc}
\hline & Distance $(\boldsymbol{\mu m})$ & Critical stress $(\mathbf{k P a})$ \\
\hline $\begin{array}{c}\text { Middle section } \\
\text { Upper corner (MS uc) } \\
\text { Middle section }\end{array}$ & 96.2 & 177.6 \\
Lower corner (MS lc) \\
Middle section \\
Middle point (MS mp) \\
$\quad$ Side section \\
Upper corner (SS uc) \\
$\quad$ Side section \\
Lower corner (SS lc) \\
Side section \\
Middle point (SS mp)
\end{tabular}

The critical stress for the cheese samples that were taken in the middle point of both sections is smaller than the critical stress of the other cheese samples, regardless of the speed at which these samples were measured. This does not necessarily mean that the forces during the cutting of these cheese samples 
are lower. Since these samples also have a lower Young's modulus, the stresses in the cheese during cutting are lower and it takes longer before a stress high enough to cause fracture is reached.

Although the upper corner in both sections had similar Young's moduli and Prony coefficients, the critical stress for fracture is lower in the side section. The measurement speed for the upper corner sample of the side section was lower than the measurement speed in the middle section $(0.1 \mathrm{~mm} / \mathrm{s}$ versus $0.5 \mathrm{~mm} / \mathrm{s}$ ). However, from the results it showed up that the effect of measurement speed is not consistent over all locations, because the cheese constitutive behavior also varies. Due to the fact that the derived critical stress is the product of different variables, i.e. Young's modulus, Prony series, deflection needed for fracture initiation and measurement speed, it is difficult to draw unambiguous conclusions.

\subsection{Validation of the stress criterion with wire cutting models}

Figure 15 shows the graphic result of the wire cutting model. Figure 16 shows an expanded view of the area around the wire.
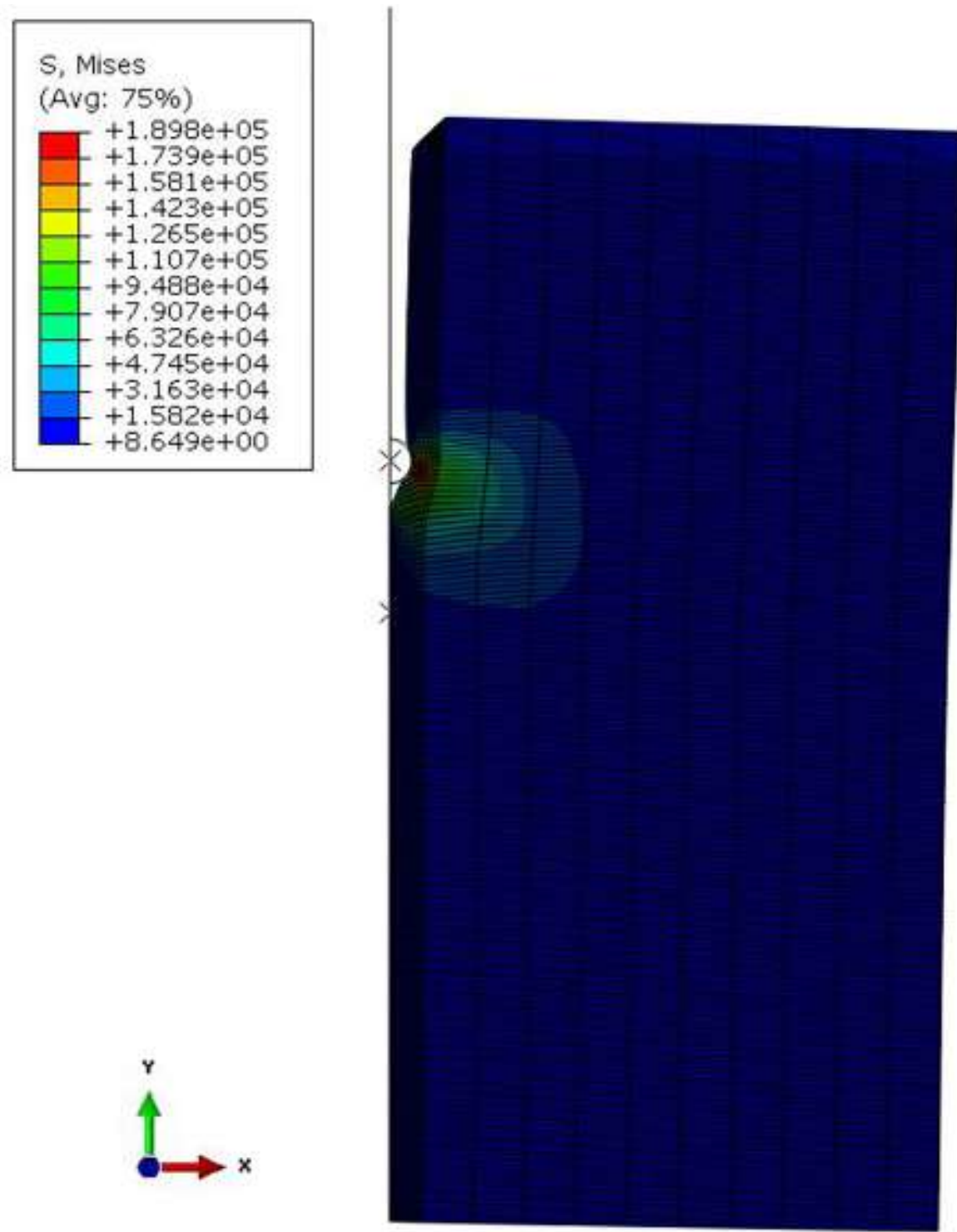

Figure 15: Graphic result of a wire cutting model 

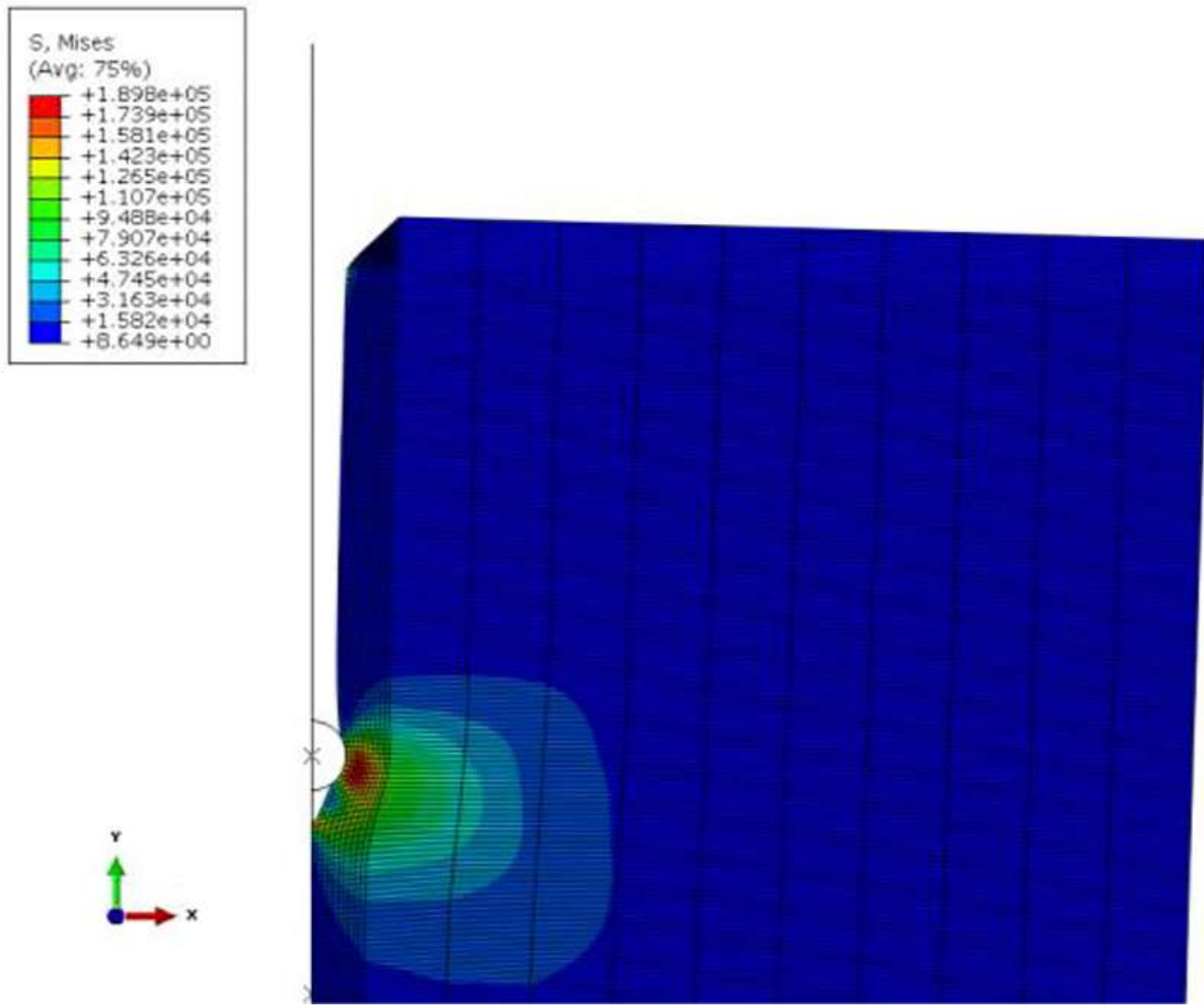

Figure 16: Graphic results of a wire cutting model in the crack tip area

The validity of the critical stress criterion determined by the method described in this chapter was tested by using the criterion in fracture experiments with another experimental set-up, i.e. the wire cutting experiments. The reaction forces on the wire were measured experimentally ( $\$ 2.5)$. In addition, simulations were performed using the experimentally determined material parameters (Young's moduli and Prony series coefficients) with a wire cutting model containing the critical stress criterion $(\S 2.7)$.

Both experimental and numerical results are shown in figure 17. Figure 17 (a) shows the results of the upper corner location in the middle cheese section. Figure 17 (b) shows the results of the upper corner location in the side section. 

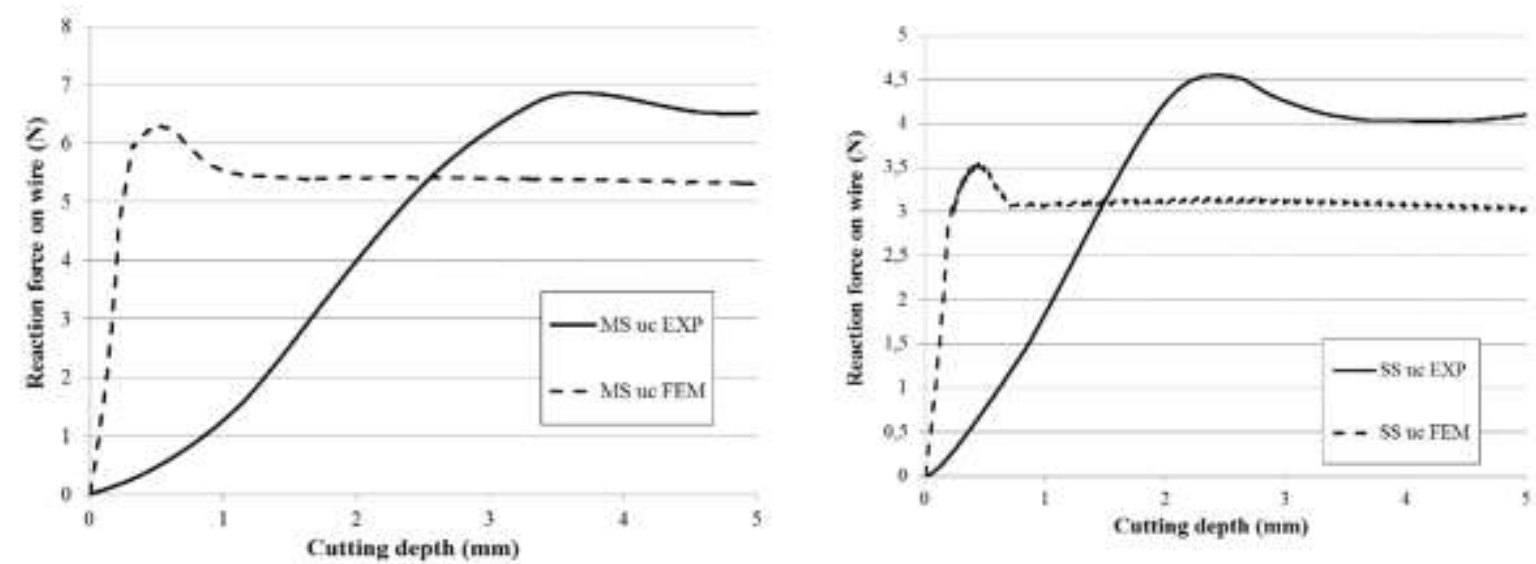

Figure 17: (a) Wire cutting results for the upper corner (uc) samples in the middle section (MS) of the cheese; (b) Wire cutting results for the upper corner (uc) samples in the side section (SS) of the cheese; EXP: experimental, FEM: finite element analysis; cutting speed $0.5 \mathrm{~mm} / \mathrm{s}$; wire diameter

\section{$1.1 \mathrm{~mm}$}

There was a clear similarity between the numerical and experimental results. Goh et al. (2003) already mentioned that the wire cutting of cheese, resulted in force-displacement curves with a difference between the indentation and the steady-state cutting phase. These two different phases are typical for indentation type cutting processes. Before the cutting initiates the substrate material will deform without breaking and the resulting force on the wire increases. Upon further loading a cut or crack initiates, the substrate opens and the wire moves into this newly created volume. This process continues with increasing force until steady state cutting is established (McCarthy et al., 2007).

The indentation and steady-state cutting phases were noticeable in both the experimental and the numerical wire cutting results of this work. Not only did the experimental and numerical data follow the same pattern, all results were also of the same order of magnitude. Furthermore, variables such as sample location, wire diameter and cutting speed had the same effect on all results. Higher experimental results were matched with higher numerical results.

The wire cutting tests and wire cutting simulations on the lower corner and the middle point samples gave similar results with a distinct indentation and steady-state cutting phase. The steady-state cutting forces of both experiments and simulations are given in table 5 .

Table 5: Experimental and numerical steady-state cutting forces in middle point and lower corner samples

\begin{tabular}{ccccc}
\hline & \multicolumn{4}{c}{ Steady-state cutting force (N) } \\
\hline & $\begin{array}{c}\text { Middle Section }- \\
\text { lower corner }\end{array}$ & $\begin{array}{c}\text { Side section }- \\
\text { lower corner }\end{array}$ & $\begin{array}{c}\text { Middle Section }- \\
\text { Middle point }\end{array}$ & $\begin{array}{c}\text { Side Section - } \\
\text { Middle point }\end{array}$ \\
\hline Experimental & 5.97 & 6.19 & 4.22 & 2.96 \\
FEM & 5.05 & 5.27 & 2.92 & 2.80 \\
\hline
\end{tabular}


Despite the prominent similarities there were also some differences between the simulations and the experiments. For each wire cutting experiment the reaction force on the wire was somewhat higher than the reaction force in the corresponding finite element models. This could possibly be explained by the friction between the wire and the cheese, which was not included in the simulations as well as the material's nonlinear viscoelastic behavior which was ignored in this study in order to keep the methods and model as simple as possible. In addition, the initial slope of the FE results was higher than the slope of the experimental results.

A possible explanation for this observation is that in the models the wire was represented as a rigid body. In the experiments however, a synthetic wire was used. The pliability of this wire could not be completely eliminated. This resulted in bending of the wire during the cutting and thus a lower increase of the stress in function of the distance compared to the model with the rigid wire. Another possible explanation is the fact that the cheese models had a small initial opening. This was necessary to enable the crack initiation. However, in the cheese samples that were cut experimentally this opening was not present. This might cause an initial indentation of the cheese samples before fracture is initiated.

\section{Conclusions}

Finite element (FE) methods can contribute considerably in the optimization of cutting processes. However, the application is often hampered due to difficulties in the modeling of product failure. In the present work, it was shown that a critical stress criterion can be determined with a combination of experiments and numerical simulations by using single edge notched bending tests.

Experimentally determined material parameters (from compression and stress-relaxation tests, and from single edge notched bending tests) were used in FE models of the bending tests. The bending necessary to initiate fracture, which is a degree of freedom in the model, was determined by using a camera with a micro lens. The fracture criterion was determined as the stress values in a node at a distance of $100 \mu \mathrm{m}$ from the crack tip. Simulations also showed that at this distance of $100 \mu \mathrm{m}$ from the crack tip, there was a convergence of the critical stress for each data set, independent of the model settings like mesh density and shape of the crack tip.

This critical stress and distance criterion was successfully validated with wire cutting experiments of cheese. The experimental and numerical results showed the same trend with a clear wire indentation and steady state cutting phase. The observed difference in forces between simulations and experiments can be explained by the yielding of the wires in the experiments, while the wires were defined as rigid bodies in the FE models.

It can be concluded that the determination of a critical stress and distance criterion further from the crack tip is a good approach to model fracture and cutting of cheese.

\section{Acknowledgements}

This research was funded by a Ph.D. grant of the Agency for Innovation by Science and Technology (Grant number IWT/09/91091). 


\section{References}

Alam, K., Mitrofanov, A.V., Silberschmidt, V.V. (2009). Finite element analysis of forces of plane cutting of cortical bone. Computational Materials Science, 46, 738-743.

Aydiner, C.C., Üstündag, E., Clausen, B., Hanan, J.C., Winholtz, R.A., Bourke, M.A.M., Peker, A. (2005). Residual stresses in a bulk metallic glass-stainless steel composite. Materials Science and Engineering, 399, 107-133.

Bona, E., da Silva, S.F., Borsato, D., Silva, L.H.M., Fidelis, D.A. (2007). Multicomponent diffusion modeling and simulation in prato cheese salting using brine at rest: The finite element method approach. Journal of Food Engineering, 79, 771-778.

Caro-Corrales, J., Cronin, K., Gao, X., Cregan, V. (2010). Heat transfer analysis of cheese cooling incorporating uncertainty in temperature measurement locations: Application to the industrial process. Journal of Food Engineering, 99, 159-165.

Chen, G., Ren, C., Zhang, P., Cui, K., Li, Y. (2013). Measurement and finite element simulation of micro-cutting temperatures of tool tip and workpiece. International Journal of Machine Tools and Manufacture, 75, 16-26.

Cregan, V., O’Brien, S.B.G., Charpin, J.P.F., Cronin, K. (2013). Temperature evolution in a partially submerged approximate cheese cylinder. Journal of Food Engineering, 115, 398-406.

Gamonpilas, C., Charalambides, M., Williams, J.G., Dooling, P.J., Gibbon, S.R. (2009). On the study of fracture properties of starch gels. In the proceedings of the $5^{\text {th }}$ International Symposium on Food Rheology and Structure, Zurich (Switzerland)

Goh, S.M., Charalambides, M.N. and Williams, J.G. (2003). Large strain time dependent behavior of cheese, Journal of Rheology, 47(3), 701-716

Goh, S.M., Charalambides, M.N., Williams, J.G. (2005). On the mechanics of wire cutting of cheese. Engineering Fracture Mechanics, 75, 931-946.

Gunasekaran, S., Ak, M.M. (2003). Cheese rheology and texture. Florida: CRC Press.

Le-Ngoc, L., McCallion, H. (2000). A cellular finite element model for the cutting of softwood across the grain. International Journal of Mechanical Sciences, 42, 2283-2301.

Lezzi, R., Francolino, S., Mucchetti, G. (2011). Natural convective cooling of cheese: predictive model and validation of heat exchange simulation. Journal of Food Engineering, 106, 88-94. 
Li, K., Gao, X.-L., Sutherland, J.W. (2002). Finite element simulation of the orthogonal metal cutting process for qualitative understanding of the effects of crater wear on the chip formation process. Journal of Materials Processing Technology, 127, 309-324.

Lucas, L., MacBeath, A., McCulloch, E., Cardoni, A. (2006). A finite element model for ultrasonic cutting. Ultrasonics, 44, 503-509.

Martiny, Ph., Lani, F., Kinloch, A.J., Pardoen, T. (2013). A maximum stress at a distance criterion for the prediction of crack propagation in adhesively-bonded joints. Engineering Fracture Mechanics, 97, 105-135.

McCarthy, C.T., Hussey, M., Gilchrist, M.D. (2007). On the sharpness of straight edge blades in cutting soft solids. Part I - indentation experiments. Engineering Fracture Mechanics, 74, 2205-2224.

McCulloch, E. (2008). Experimental and finite element modeling of ultrasonic cutting of food. $\mathrm{PhD}$ thesis, University of Glasgow.

Salahshoor, M., Guo, Y.B. (2014). Finite element simulation and experimental validation of residual stresses in high speed dry milling of biodegradable magnesium-calcium alloys. International Journal of Mechanical Sciences, 80, 153-159.

Shet, C., Deng, X. (2003). Residual stresses and strains in orthogonal metal cutting. International Journal of Machine Tools and Manufacture, 43, 573-587

Shet, C., Deng, X., Bayoumi, A.E. (2003). Finite element simulation of high-pressure water-jet assisted metal cutting. International Journal of Mechanical Sciences, 45, 1201-1228

Vandenberghe, E., Choucharina, S., De Ketelaere, B., De Baerdemaeker, J., Claes, J. (2014). Spatial variability in fundamental material parameters of Gouda cheese. Journal of Food Engineering, 131, $50-57$. 